\title{
An Experimental Study of Vehicle 1st Order Vibration Improvement at Engine Idle
}

\author{
Hui-Min Shen \\ School of Mechanical Engineering, University of Shanghai for Science and Technology, 516 Jungong Road, Shang- \\ hai, 200093, China. \\ State Key Laboratory of Fluid Power Transmission and Control, Zhejiang University, 866 Yuhangtang Rd, \\ Hangzhou, 310058, China.
}

\section{Pei Tang}

SAIC Motor Technical Center, 201 Anyan Road, Shanghai, 201804, China.

\section{Feng Bian and Xiang-Wei Wu}

School of Mechanical Engineering, University of Shanghai for Science and Technology, 516 Jungong Road, Shanghai, 200093, China.

\author{
Wen-Jie Zhao and Liang-Liang Hu \\ SAIC Motor Technical Center, 201 Anyan Road, Shanghai, 201804, China.
}

\section{(Received 15 April 2020; accepted 31 August 2020)}

\begin{abstract}
An experimental study of the $1^{\text {st }}$ order vibration improvement at engine idle condition of a malfunctional vehicle in development is presented in this work. Firstly, the generation mechanism of the vehicle $1^{\text {st }}$ order vibration problem at engine idle is analyzed based on theoretical analysis. Then, experiments are designed to derive the possible vibration excitation source and transfer path through comprehensive analysis. The powertrain rotational system imbalance exceeding a limit is determined to be the main reason for the vehicle $1^{\text {st }}$ order abnormal vibration. The resonance of the mounting system excited by the powertrain rotational system intensifies the $1^{\text {st }}$ order abnormal vibration. Experimental analyses show that the clutch imbalance severely exceeds the prescribed limit, which confirms the diagnosis of the excitation source, and a significant improvement of about $87 \%$ of the $1^{\text {st }}$ order vibration can be achieved by adjusting the clutch imbalance.
\end{abstract}

\section{NOMENCLATURE}

$C O V \quad$ coefficient of Variation of IMEP

$\delta \quad$ inter-cylinder pressure imbalance

$S T D \quad$ standard deviation of IMEP in the measured cycles

$I M E P \quad$ Indicated Mean Effective Pressure

$I M E P_{\max }$ the maximum values of $I M E P$ in the four cylinders of all cycles

$I M E P_{\min } \quad$ the minimum values of IMEP in the four cylinders of all cycles

$I M E P_{\text {mean }}$ the mean value of the four cylinders' $I M E P$

$a_{1} \quad$ the weighted $1^{\text {st }}$ order vibration acceleration

$a_{X}, a_{Y}, a_{Z}$ acceleration value of the $\mathrm{X}$-axis, Y-axis and $\mathrm{Z}$-axis at the $1^{\mathrm{st}}$ order frequency, respectively

\section{INTRODUCTION}

Intensified competition in the passenger vehicle market and constant pursuit by consumers of travel quality is leading to continuous modification of the driving experience. ${ }^{1-3}$ Besides, the decreasing gap between the vehicles' appearance brings more attention to vehicle dynamic performance. As the direct manifestation of the vehicle dynamic performance, $\mathrm{NVH}$ (Noise, Vibration, and Harshness) is the intuitive feedback of passengers' tactile and auditory sense, and its level has become one of the most important factors in vehicle quality judgement. ${ }^{2,4}$ The NVH property is not confined to vehicle dynamic characteristics study, which is the key design attributes of high- speed transmission. ${ }^{5}$ Research by use of experimental test, theoretical modeling and finite element simulations is carried out to realize effective vibration control. ${ }^{6,7}$

When the engine is in the idle condition, passengers will be more sensitive to vibration, which is frequently encountered in a traffic jam or whilst waiting for a traffic light. Besides, if the vehicle vibration frequency is close to the natural frequency of human organs, vibration not only affects the driving experience, but also causes passenger fatigue. In particular, severe low-frequency vibrations, especially the $1^{\text {st }}$ order vibration at engine idle, may cause extreme discomfort and even endanger the passengers' health. Thus, research progress on low-frequency vibration at idle condition will provide important technical support for driving comfort improvement.

Research on vehicle vibration at engine idle is carried out using simulation or experimental ${ }^{8}$ techniques from the aspects including the generation mechanism, ${ }^{9}, 10$ vibration source, ${ }^{11,12}$ and transfer path. ${ }^{11,13}$ The simulation investigations focus on the generation mechanism from a systematic standpoint. A multi-body dynamic model capable of handling non-steady state and non-linear analysis was developed in ${ }^{9}$ to predict lowfrequency vibration caused by the powertrain. In, ${ }^{10}$ a full functional digital car model is developed to analyze and discuss idle shake using multi-body simulations. ${ }^{12}$ proposed an integrated modelling and optimization approach for steady-state and transient tune-up of an engine at idle speed.

On the other hand, experimental researchers make effort in deriving the excitation source or propagation path of vibra- 
tion and noise. Different vibration analysis techniques for engine idle vibration are compared in, ${ }^{14}$ which indicates that the closeness of the powertrain pitching mode to the fundamental excitation frequency at full load, with elevated vehicle idle speed, results in higher vibration transmissibility. A quantified measurement method for engine idle roughness was proposed $\mathrm{in}^{15}$ by using engine brake torque data. ${ }^{16}$ introduces an engine combustion stability evaluation method based on certain calibrated parameters to reduce adverse impacts on vehicle idle quality. Besides, methods for isolation or absorption vibration were also studied. In, ${ }^{17}$ a semi-active hydraulic damping strut was designed to provide high damping for effective vibration isolation. A hybrid proportional electromagnetic dynamic vibration absorber was developed in ${ }^{18}$ for engine vibration control during idle condition, which reduced about $48 \%$ and $57 \%$ of the primary mass RMS acceleration response under excitations at $20 \mathrm{~Hz}$ and $27 \mathrm{~Hz}$ respectively. However, the existing experimental research focused on single influence factor analysis of vibration at idle condition, and comprehensive experimental analysis of vehicle idle vibration is insufficient.

At idle condition, vibration sensed by passengers is dominated by the powertrain vibration. To solve the $1^{\text {st }}$ order abnormal vibration problem at idle condition of a vehicle in development, this paper comprehensively analyzed the generation mechanism through the excitation sources and transfer paths. The effects, including the engine combustion, the powertrain rotational system imbalance, mounting system, exhaust hangers, drive half shafts, and powertrain pipes, on the $1^{\text {st }}$ order vibration at idle condition is analyzed and discussed experimentally. Then, the root cause of the $1^{\text {st }}$ order abnormal vibration was figured out, and the $1^{\text {st }}$ order vibration of the malfunctional vehicle at idle condition was significantly reduced by adjusting the clutch imbalance.

This paper is organized as follows:

- Section 2 describes the vehicle $1^{\text {st }}$ order vibration problem at engine idle and analyzes the possible generation mechanism in theory.

- In Section 3, comprehensive analyses of vibration excitation source and transfer path are carried out based on experiments, and imbalance beyond the prescribed limit of the powertrain rotational system is determined to be the main reason of the vehicle $1^{\text {st }}$ order abnormal vibration, which is intensified by the resonance of the mounting system.

- Section 4 presents the $1^{\text {st }}$ order vibration control method by adjusting the clutch imbalance to realize total imbalance excitation reduction of the powertrain rotational system, and experiments are conducted for validation.

- Section 5 summarizes and discusses the experimental results.

\section{MECHANISM ANALYSIS OF THE $1^{\text {ST }}$ ORDER VIBRATION AT IDLE CONDITION}

Both subjective and objective methods can be applied for vehicle vibration evaluation at idle condition. For the former one, vibration as a tactile sensation can be perceived in a vehicle, such as seats, and can be scored by the intuitive sensation of developers. The objective evaluation method measures the vibration level with acceleration sensors. In this paper, both the subjective and objective evaluation methods are applied to solve the $1^{\text {st }}$ order abnormal vibration problem at idle condition of a vehicle in development. Firstly, systematic analysis is carried out to figure out the excitation sources and transfer paths.

\subsection{Problem Description}

A front-wheel-drive vehicle in development is equipped with a four-cylinder four-stroke engine (hot engine idle speed of $700 \mathrm{r} / \mathrm{min}$ ) and a dual-clutch transmission. During the development procedure, subjective driving evaluations of the prototype vehicles scored by the engineers are as follows,

- For all vehicles of this type in development, the lowfrequency vibration was not obvious at cold engine idle with engine speed decreases from $1200 \mathrm{r} / \mathrm{min}$ to 900 $\mathrm{r} / \mathrm{min}$.

- However, when the idle speed decreases to $700 \mathrm{r} / \mathrm{min}$, a noticeable low-frequency vibration can be felt in part of the vehicles, whose subjective score by the engineers is unacceptable 5 out of 10 .

- Subjective evaluation of malfunctional vehicle vibration is mainly a continuous low-frequency twitch with signal modulation characteristics.

In order to quantify this low-frequency vibration, the acceleration levels of the driver's seat rail of Vehicle A (one of the malfunctional vehicles) are compared with a healthy vehicle of the same type in development using the LMS Test Lab system (LMS Engineering Innovation Inc.) and accelerometers (HT356A33, PCB Piezotronics Inc.). The coordinate system is established as, $\mathrm{X}$-axis points from the front to back direction of the vehicle, Y-axis points from the left to right direction, and $\mathrm{Z}$-axis is assigned with the vertical direction. The monitored results are presented in Fig. 1. It can be observed that significant peak vibrations on all axes happen at frequencies of 11.7 Hz and $23.3 \mathrm{~Hz}$ of the malfunctional Vehicle A compared with the healthy vehicle, which corresponds to the $1^{\text {st }}$ and $2^{\text {nd }}$ order engine frequencies respectively. Vibration amplitude can be detected on the $\mathrm{X}$ and $\mathrm{Z}$ axes, and the amplitude of the $1^{\text {st }}$ order vibration (at $11.7 \mathrm{~Hz}$ ) is significantly higher than that of the $2^{\text {nd }}$ order vibration (at $23.3 \mathrm{~Hz}$ ). Combined with the subjective evaluation results, it can be affirmed that the abnormal vehicle idle vibration is caused by the $1^{\text {st }}$ order vibration (at $11.7 \mathrm{~Hz}$ ).

\subsection{Generation Mechanism Analysis}

In order to derive the cause of this abnormal idle vibration problem, the generation mechanism from the point of excitation source-transfer path-response is studied. As illustrated in Fig. 2, the relationship between the excitation source, transfer path and response of this malfunctional vehicle idle vibration is analyzed theoretically.

For the excitation sources, the powertrain system induced vibration is the main excitation source for vehicle idle vibration. At idle condition, the combustion torque of the engine only overcomes the friction resistance brought by the powertrain rotational system and the vehicle electrical load, which is a small load condition. Therefore, the engine is prone to unstable combustion, resulting in the $0.5^{\text {th }}$ and $1^{\text {st }}$ order excitation. ${ }^{16}$ In addition, except for the powertrain rotational system imbalance, involving the crankshaft, crankshaft vibration damper, dual-mass flywheel (DMF) and clutch, the imbalance caused by misalignment between adjacent components of the 


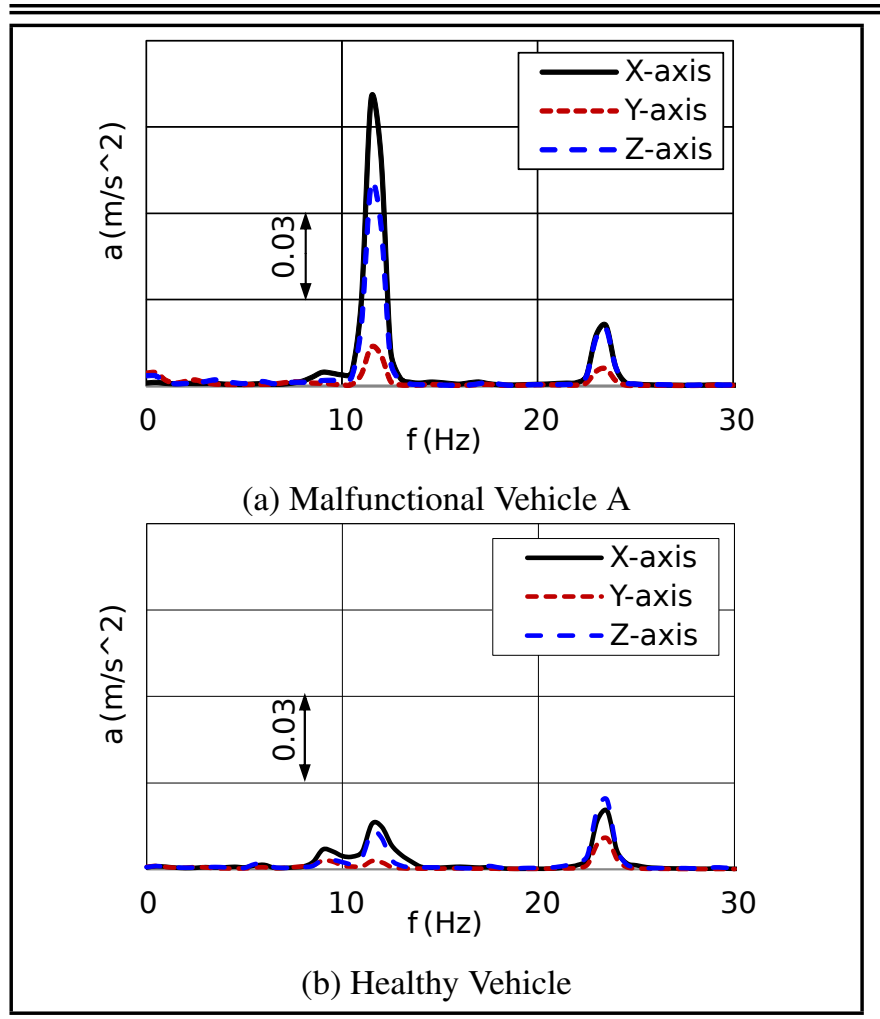

Figure 1. Acceleration levels as a function of frequency at the driver's seat rail of the malfunctional Vehicle A and a healthy vehicle of the same type.

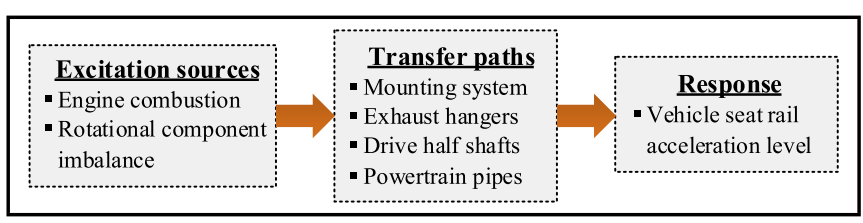

Figure 2. Generation mechanism of the $1^{\text {st }}$ order vibration at idle condition.

powertrain rotational assembly will generate the $1^{\text {st }}$ order excitation when idling. The excitation coupling of the unstable combustion and the rotational system imbalance also increases the difficulty of analyzing and solving the $1^{\text {st }}$ order abnormal vibration problem at idle condition.

According to the transmission and installation relationship, the transfer paths of idle vibration to the vehicle body include the powertrain mounting system, exhaust hangers, drive half shafts, and powertrain pipes (air-conditioning pipes, warm water pipes, etc.). Specifically, the vibration detected inside the vehicle (such as seat rail) is a superposition of the vibrations transferred over the above paths.

\section{ANALYSIS OF EXCITATION SOURCES AND TRANSFER PATHS}

\subsection{Analysis of Excitation Sources}

As mentioned above, the candidate excitation sources of the $1^{\text {st }}$ order vibration at idle condition from the powertrain system could only involve:

- Engine combustion excitation: Abnormal combustion in two cylinders of the four-cylinder four-stroke engine will lead to the $1^{\text {st }}$ order vibration excitation.

- Powertrain rotational system imbalance: The imbalance of rotational assembly component or imbalance caused

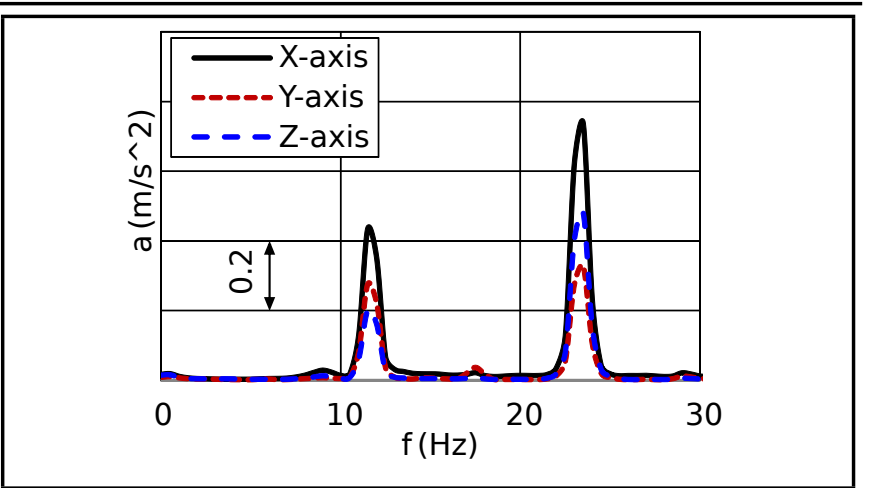

Figure 3. Powertrain body acceleration spectrum of the malfunctional Vehicle A.

by misalignment between adjacent components will also generate the $1^{\text {st }}$ order vibration excitation.

Figure 3 gives the monitored powertrain body vibration spectrum of the malfunctional Vehicle A. Obvious vibration peaks at $11.7 \mathrm{~Hz}$ and $23.3 \mathrm{~Hz}$ can be observed. The $23.3 \mathrm{~Hz}$ peak is the $2^{\text {nd }}$ order vibration excitation of four-cylinder fourstroke engine due to reciprocating inertial force and combustion, which belongs to normal excitation of the engine. The comparisons of Figs. 1(a) and 3 imply that,

- The vibration level of the $2^{\text {nd }}$ order idle frequency (23.3 $\mathrm{Hz}$ ) is smaller than $0.04 \sim 0.05 \mathrm{~m} / \mathrm{s}^{2}$, which is reduced by a factor of several dozen from the powertrain to the vehicle seat. This verifies that the powertrain mounting system effectively isolates this $2^{\text {nd }}$ order vibration generated by the engine excitation.

- Although, the vibration level of the $1^{\text {st }}$ order idle frequency $(11.7 \mathrm{~Hz})$ detected on the vehicle seat also decreases to about a quarter of the powertrain vibration, it is obviously larger than $0.03 \mathrm{~m} / \mathrm{s}^{2}$, which results in an unacceptable subjective score of 5 (out of 10) by the engineers. Besides, the $1^{\text {st }}$ order vibration becomes apparently obvious compared with the $2^{\text {nd }}$ order vibration on the vehicle seat than on the powertrain body.

- The proportion change of the $1^{\text {st }}$ and $2^{\text {nd }}$ order vibrations from the powertrain to the vehicle seat indicates that the powertrain mounting system could not effectively attenuate the $1^{\text {st }}$ order vibration excitation compared with the $2^{\text {nd }}$ order vibration. Therefore, the $1^{\text {st }}$ order vibration generated by the powertrain is assessed to be the excitation source of the malfunctional vehicle.

\subsubsection{Analysis of engine combustion excitation}

Since the $1^{\text {st }}$ order reciprocating inertial force of a fourstroke inline four-cylinder engine is balanced, only the $1^{\text {st }}$ order excitation caused by unstable engine combustion needs to be considered. Methods for engine combustion stability evaluation include the cylinder pressure fluctuation method ${ }^{19}$ and the crankshaft speed fluctuation method. ${ }^{16,20}$ The former is a direct assessment method, whilst the latter is an indirect assessment method. Although the crankshaft speed fluctuation method is simpler, it is difficult to separate the influence brought by the rotational system imbalance. Therefore, we take the cylinder pressure fluctuation method for engine combustion stability evaluation at idle condition, which is based on the Indicated Mean Effective Pressure (IMEP) during the measurement cycles. 
Table 1. Comparison of combustion stability at engine hot idle with competition vehicles.

\begin{tabular}{|l|l|l|l|l|l|l|}
\hline \multirow{2}{*}{ Subject } & Vibration & \multicolumn{4}{|c|}{ COV/\% } & \multirow{2}{*}{$\delta / \%$} \\
\cline { 3 - 7 } & complaint & Cylinder 1 & Cylinder 2 & Cylinder 3 & Cylinder 4 & \\
\hline Vehicle A & Yes & 6.4 & 7.5 & 7.0 & 8.2 & 4.5 \\
Vehicle C1 & No & 10.5 & 11.1 & 12.0 & 11.8 & 7 \\
Vehicle C2 & No & 8.4 & 8.4 & 7.1 & 8.2 & 5 \\
\hline
\end{tabular}

The combustion uniformity of a certain cylinder is characterized by the Coefficient of Variation (COV) of IMEP, as defined in Eq. (1). Then, the largest difference in combustion between different cylinders is quantified by the inter-cylinder pressure imbalance $\delta$, as defined in Eq. (2). The smaller the $C O V$ and $\delta$ values are, the better the engine idle stability is. The definitions are as follows:

$$
\begin{gathered}
C O V=\frac{S T D}{I M E P} \times 100 \% \\
\delta=\frac{I M E P_{\max }-I M E P_{\min }}{I M E P_{\text {mean }}} \times 100 \% ;
\end{gathered}
$$

where $S T D$ is the standard deviation of IMEP in the measured cycles; $I M E P_{\max }$ and $I M E P_{\min }$ are the maximum and minimum values of $I M E P$ in the four cylinders of all cycles, respectively; $I M E P_{\text {mean }}$ is the mean value of the four cylinders' IMEP.

Based on evaluation criteria defined above, the hot idle cylinder pressures of the malfunctional Vehicle A and two competition vehicles of other brands without abnormal vibration (named Vehicle $\mathrm{C} 1$ and $\mathrm{C} 2$ ) were monitored using spark plug cylinder pressure sensors, a kibox combustion analyzer (Kistler Inc.) and post-processing software. The analysis process is 300 combustion cycles per cylinder. The comparison results of hot idle combustion stability presented in Tab. 1 show that the malfunctional Vehicle $\mathrm{A}$ is lower than the competition Vehicles $\mathrm{C} 1$ and $\mathrm{C} 2$ both in the single-cylinder stability parameter $C O V$ and inter-cylinder stability parameter $\delta$. The comparison results verify that idle combustion stability of Vehicle $\mathrm{A}$ is better than that of the competition vehicles.

Besides, in order to illustrate the correlation between the engine cylinder pressures and vibrations of the powertrain and seat rail at the time of significant vibration complaint, Fig. 4 gives the synchronous signals of Vehicle A, involving cylinder pressures, powertrain vibration, and seat rail vibration. Among them, it can be observed that the obvious $1^{\text {st }}$ order and $2^{\text {nd }}$ order vibration modulations exist in the synchronous signals of the powertrain and seat rail. The vibration spectrum in Fig. 1 implies that the main component of the seat rail vibration modulation signal in Fig. 4 is the $1^{\text {st }}$ order vibration. In Fig. 4, the cylinder pressure distribution of the four cylinders is uniform with normal curve and peak shape. In addition, there are no obvious misfires, knocks, and out of cylinders in the whole process. All the above discussions verify that the combustion of the malfunctional Vehicle A is stable. This excludes the engine combustion excitation as the excitation sources that cause the $1^{\text {st }}$ order vibration of Vehicle A at hot idle condition.

\subsubsection{Analysis of imbalance excitation from power- train rotational system}

At idle condition, the internal rotating components of the transmission could be neglected. The powertrain rotational system involves the crankshaft, crankshaft vibration damper, DMF and clutch. On the other hand, since the transmission ratios of the engine rotating components to the crankshaft do not equal 1 , including the engine timing chain, camshaft, water pump and electric generator, their imbalances will not cause

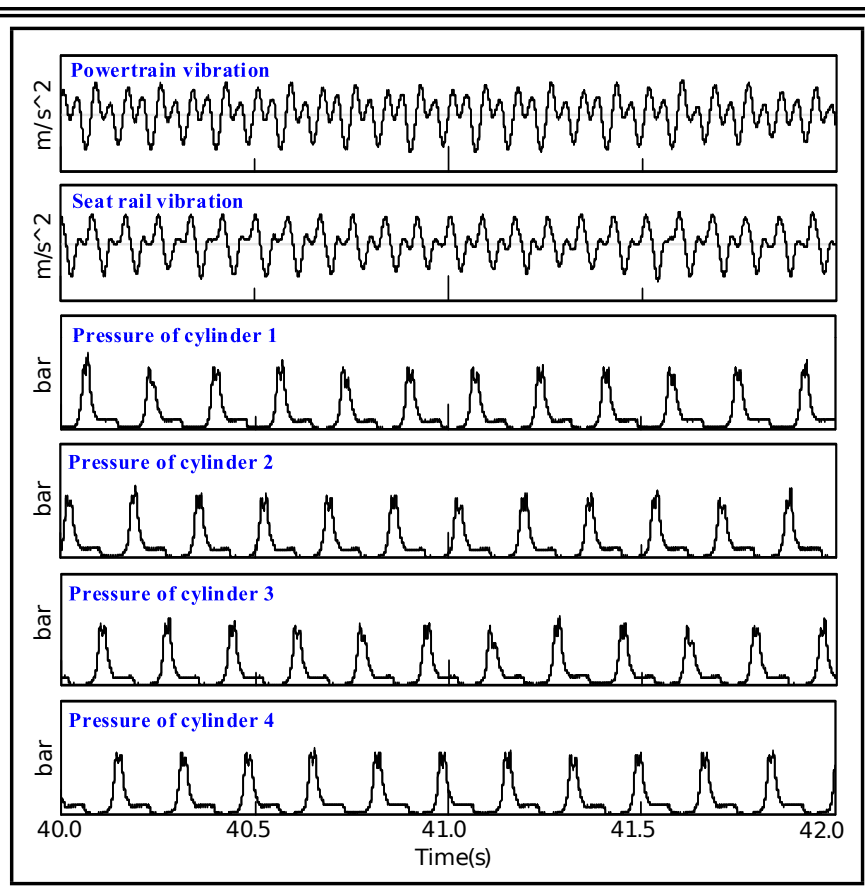

Figure 4. Synchronous signals of vibrations and cylinder pressures of Vehicle A.

Table 2. Upper control ranges of imbalance for powertrain rotational components.

\begin{tabular}{|l|l|}
\hline Rotational components & Imbalance $/(\mathrm{g} \cdot \mathrm{mm})$ \\
\hline Crankshaft & $120-200$ \\
Crankshaft vibration damper & $150-200$ \\
DMF & $300-500$ \\
Clutch & $600-2000$ \\
\hline
\end{tabular}

the $1^{\text {st }}$ order vibration. Thus, their imbalances are out of consideration. Tab. 2 gives the upper imbalance control ranges of the powertrain rotational components in the vehicle industry. In practical production, the imbalances of the crankshaft, crankshaft vibration damper and DMF are usually controlled through completely offline inspection.

However, due to offline inspection deficiency, the clutch imbalance, which takes the largest proportion of the powertrain rotational system imbalance, mainly relies on processing precision and assembly technology. The clutch is constructed with a driving part and a driven part. During engine idle, only the driving part participates in rotation, while the driven part keeps still. Besides, the imbalance of the simple driven part structure is minor. It is reasonable to speculate that the clutch imbalance is induced by the driving part. This could result in a great risk of exceeding the control standard for the clutch imbalance.

In order to study the influence of the powertrain rotational system imbalance on the $1^{\text {st }}$ order vibration at idle condition, we measured the vibrations at different conditions by adjusting the installation angles between the clutch and DMF of malfunctional Vehicle $A$ and another malfunctional vehicle of the same type (termed Vehicle B). During the adjustment process, the relative positions of the crankshaft, crankshaft vibration damper and DMF are kept constant, and the imbalance of subsystem combined with the three components remains unchanged. The clutch and DMF are connected by 3 bolts with an interval of $120^{\circ}$. Thus, the powertrain rotational system can still be installed when the clutch rotates $120^{\circ}$. Nevertheless, the total imbalance of the entire powertrain rotational system at idle condition varies after rotating $120^{\circ}$. We define the 
Table 3. Comparison of the $1^{\text {st }}$ order vibration acceleration values before and after adjusting the DMF-clutch connection angle.

\begin{tabular}{|l|l|l|l|l|}
\hline \multirow{2}{*}{ Subject } & \multicolumn{1}{|c|}{ Powertrain vibration $\left(\mathrm{m} / \mathrm{s}^{\wedge}\right)$} & \multicolumn{2}{|c|}{ Seat rail vibration $\left(\mathrm{m} / \mathrm{s}^{\wedge} 2\right)$} \\
\cline { 2 - 5 } & Original state & Adjust $120^{\circ}$ & Original state & Adjust $120^{\circ}$ \\
\hline Vehicle A & 0.524 & 0.417 & 0.122 & 0.091 \\
Vehicle B & 0.458 & 0.282 & 0.094 & 0.062 \\
\hline
\end{tabular}

weighted $1^{\text {st }}$ order vibration acceleration $a_{1}$ as

$$
a_{1}=\sqrt{a_{x}^{2}+a_{y}^{2}+a_{z}^{2}}
$$

where $a_{X}, a_{Y}$ and $a_{Z}$ are acceleration value of the X-axis, Y-axis and Z-axis at the $1^{\text {st }}$ order frequency, respectively.

Tab. 3 shows the $1^{\text {st }}$ order vibration acceleration values before and after adjusting the DMF-clutch connection angle randomly. It can be seen that the $1^{\text {st }}$ order vibrations for both the powertrains and seat rails are reduced significantly with the connection angle adjusted by $120^{\circ}$. The reduction range can reach about $25 \%$ to $35 \%$, indicating that the imbalance of the powertrain rotational system has a significant impact on the vehicle $1^{\text {st }}$ order vibration at idle condition.

\subsection{Analysis of Transfer Paths}

At idle condition, powertrain vibration is transferred to the vehicle body through four main paths, including the powertrain mounting system, exhaust hangers, drive half shafts, and powertrain pipes (air-conditioning pipes, warm water pipes, etc.), as illustrated in Fig. 2. Among them, the mounting system is the most complex transfer path, and discussions about the other three transfer paths is carried out separately from it.

\subsubsection{Vibration transfer paths analysis of exhaust hangers, drive half shafts and powertrain pipes}

The transfer paths of the exhaust hangers, the drive half shafts and the powertrain pipes are connected to the vehicle body by multi connection points. This makes the measurement signals closely coupled. Objective evaluation will lead to a significant amount of work, and the coupling relationship will make it difficult to accurately determine the impact of each path. Therefore, the method of subjective evaluation by disconnecting a single transfer path is adopted here. Each transfer path is disconnected as follows:

- Disconnect the exhaust hangers: Disconnect all hangers of the exhaust system from the sub-frame and vehicle body, and the exhaust system is supported on the ground by rubber blocks.

- Disconnect the drive half shafts: Remove the drive half shafts from the transmission, whilst avoiding leaking lubricating oil.

- Disconnect the powertrain pipes: Disconnect the airconditioning pipes and the warm water pipes from the vehicle body; since the intercooler pipes and the cooling water pipes are connected to the engine Condenser Radiator Fan Module (CRFM) and the CRFM is elastically connected to the vehicle body again, the vibration transfer of them does not need to be considered.

Tab. 4 shows the subjective evaluation results of the $1^{\text {st }}$ order vibration of Vehicle A after the transfer path is disconnected in sequence at hot idle condition. It can be seen that the $1^{\text {st }}$ order vibration state inside the vehicle is not significantly changed when the three transfer paths are disconnected separately. This verifies that none of these three transfer paths is the main transfer path of the $1^{\text {st }}$ order vibration.
Table 4. Subjective evaluation results of the 1st order vibration of Vehicle A after the transfer path is disconnected in sequence at hot idle condition.

\begin{tabular}{|l|l|}
\hline Disconnected paths & Subjective scores \\
\hline Exhaust hangers & 5 \\
Drive half shafts & 5 \\
Powertrain pipes & 5 \\
\hline
\end{tabular}

Table 5. Powertrain rigid modal analysis.

\begin{tabular}{|l|l|l|l|l|l|l|}
\hline Order & 1 & 2 & 3 & 4 & 5 & 6 \\
\hline Frequency /Hz & 8.18 & 10.16 & 10.67 & 12.81 & 13.94 & 16.11 \\
Modal shape & Lateral & Pitch & Bounce & Roll & Fore-aft & Yaw \\
\hline
\end{tabular}

\subsubsection{Vibration transfer analysis of powertrain mounting system}

The rigid modal frequency and decoupling degree of the powertrain system are determined by the installation position and stiffness design of the powertrain mounting system, which may have significant influence on the idle vibration. The malfunctional Vehicle A adopts a three-point type mounting system. The powertrain rigid modal analysis is displayed in Tab. 5. The modal frequency of the Bounce $(10.67 \mathrm{~Hz})$ and the Roll $(12.81 \mathrm{~Hz})$ is close to the $1^{\text {st }}$ order idle frequency $(11.7$ $\mathrm{Hz}$ ). There is a possibility that resonance happens in the powertrain mounting system.

In order to analyze the influence of the excitation frequency on the transfer characteristics of the mounting system, a frequency sweep test is performed with different engine speeds on the malfunctional Vehicle A. The speed increases from 640 $\mathrm{r} / \mathrm{min}$ to $900 \mathrm{r} / \mathrm{min}$ with a speed interval of $20 \mathrm{r} / \mathrm{min}$, which is corresponding to the $1^{\text {st }}$ order frequency range of $10.67 \mathrm{~Hz}$ to $15 \mathrm{~Hz}$ with a frequency interval of $0.33 \mathrm{~Hz}$. The $1^{\text {st }}$ order vibration result of sweeping frequency is shown in Fig. 5. The relationship between the imbalance excitation force generated by the powertrain rotational system and the engine speed satisfies a quadratic curve. Thus, there will be no peak for the $1^{\text {st }}$ order vibration of the powertrain and seat rail if the $1^{\text {st }}$ order vibration is caused only by the powertrain rotational system imbalance. However, test results in Fig. 5 show that there are two significant peaks for the $1^{\text {st }}$ order vibration of the powertrain and seat rail between $650 \mathrm{r} / \mathrm{min}$ and $750 \mathrm{r} / \mathrm{min}$, which verifies that the obvious resonance happens in the powertrain mounting system. This indicates that the imbalance excitation of the powertrain during this speed range is amplified by the mounting system. The result coincides with the engine speed of $700 \mathrm{r} / \mathrm{min}$ when significant Vehicle A vibration occurs.

The $1^{\text {st }}$ order vibration peaks are around $700 \mathrm{r} / \mathrm{min}$, which is corresponding to the hot idle engine speed. To weaken the resonance, reduction of the powertrain mounting system stiffness

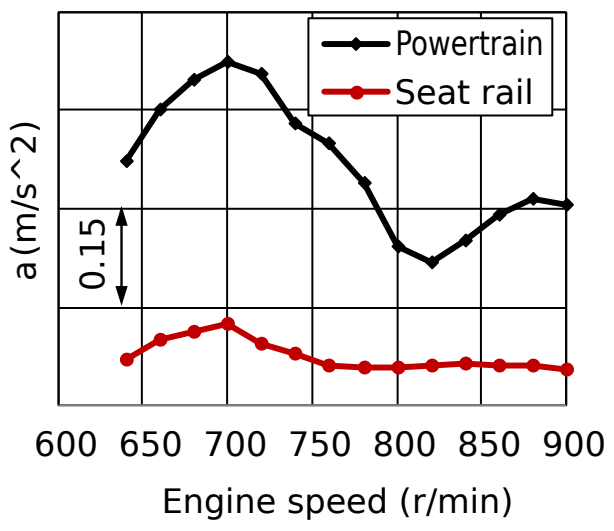

Figure 5. Vibration result of sweeping frequency. 
Table 6. $1^{\text {st }}$ order vibration level before and after the mounting system stiffness change.

\begin{tabular}{|l|l|l|}
\hline Test status & Powertrain vibration $/\left(\mathrm{m} / \mathrm{s}^{\wedge} 2\right)$ & Seat rail vibration $/\left(\mathrm{m} / \mathrm{s}^{\wedge} 2\right)$ \\
\hline Original state & 0.524 & 0.122 \\
Reduce stiffness & 0.453 & 0.101 \\
\hline
\end{tabular}

is a preferred choice. The stiffness of the mounting system cannot be sharply reduced to avoid affection on its fatigue life. We realized a $10 \%$ to $20 \%$ stiffness reduction by selecting more precise components provided by the supplier. The test results show that the static stiffness of the engine mounting, transmission mounting and lower tie bar mounting have been decreased by $12.11 \%, 16.44 \%$ and $20.36 \%$, respectively. Thus, the modal frequency of the rigid powertrain is reduced with the mounting system stiffness decrease. These efforts in powertrain rigid modal frequency decrease will weaken the resonance around $700 \mathrm{r} / \mathrm{min}$. The $1^{\text {st }}$ order vibration level before and after the mounting system stiffness change are compared in Tab. 6. It can be seen that the vibration of the powertrain and seat rail declines after the mounting system stiffness decreases, and a descent rate of $13 \%$ and $17 \%$ for the powertrain and seat rail can be achieved, respectively. However, the improvement is not as good as the results of adjusting the powertrain rotational system imbalance shown in Tab. 3 (about $25 \%$ to $35 \%$ ). The impact of the excitation induced by the powertrain rotational system imbalance on the vehicle $1^{\text {st }}$ order abnormal vibration is greater than the resonance effect brought by the mounting system during vibration transfer.

\section{EXPERIMENTAL VALIDATION OF THE $1^{\text {ST }}$ ORDER VIBRATION IMPROVEMENT}

The above analysis of the excitation sources and transfer paths shows that the $1^{\text {st }}$ order vibration of the malfunctional Vehicle A at idle condition is mainly caused by the mounting system resonance excited by the powertrain rotational system imbalance. The quality of the $1^{\text {st }}$ order vibration would be better improved, if both the imbalance excitation and the transfer path can be effectively controlled. However, due to the variable rubber characteristics, it is difficult to obtain mounting components with completely consistent performance during the mass production process. The deviation is typically about $\pm 10 \%$ in mounting stiffness. Since large reduction of the mounting system stiffness will have negative impact on its fatigue life, accurately reducing the stiffness at small-scale is difficult to realize in mass production. Therefore, imbalance excitation control of the powertrain rotational system is the preferred choice to solve this $1^{\text {st }}$ order abnormal vibration problem at idle condition for malfunctional vehicles in development. Here, experiments were carried out on Vehicle A to realize the $1^{\text {st }}$ order vibration improvement.

The upper control range of powertrain rotational component imbalance, presented in Tab. 2, shows that the clutch imbalance is almost five times that of the other three components and accounts for absolute proportion in the powertrain rotational system. Reduction of the clutch imbalance can affect the total imbalance amount of the powertrain rotational system significantly. Thus, we try to measure and improve the clutch imbalance after disconnecting the clutch from the DMF. The installation angles between the clutch and the DMF were marked so they could be kept the same after reinstallation. In order to install the clutch on the test machine, dedicated tooling was designed and manufactured to deal with the complex structure of the clutch.

Then, experiments were carried out on the imbalance test machine shown in Fig. 6(b) as follows:

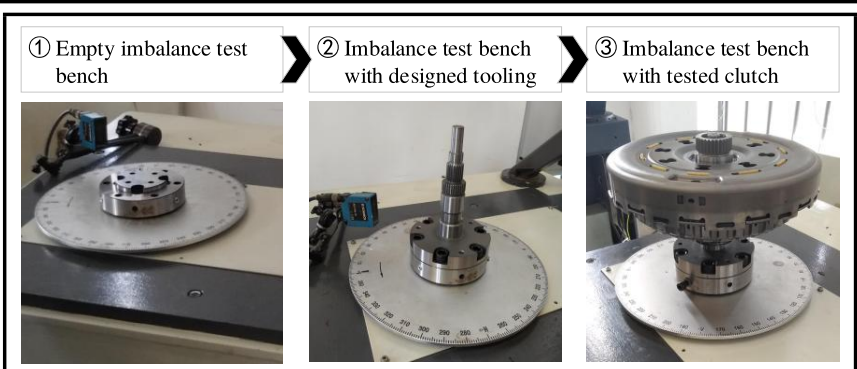

(a) Test-bench procedure for clutch evaluation of Vehicle A.

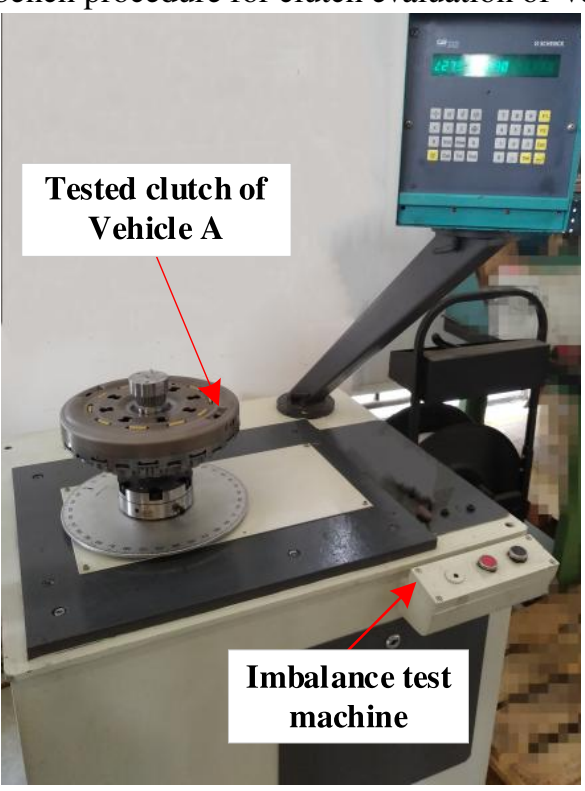

(b) Clutch imbalance detection setup

Figure 6. Clutch imbalance adjustment of the malfunctional Vehicle A.

1) Tooling imbalance control: As illustrated in Fig. 6(a), the designed tool is firstly installed to the imbalance test machine, whose imbalance is adjusted to $5.6 \mathrm{~g} \cdot \mathrm{mm}$ by repetitive test and bolts adjustment to avoid influence on the clutch test results.

2) Clutch imbalance detection: Then, the clutch of Vehicle A is installed on the imbalance test machine with the help of the designed tooling, as illustrated in Fig. 6(a). The test result of its imbalance is $3734.3 \mathrm{~g} \cdot \mathrm{mm}$, which is far beyond the industry design standard requirement listed in Tab. $2(600 \sim 2000 \mathrm{~g} \cdot \mathrm{mm})$. This also verifies the analysis about the powertrain imbalance induced $1^{\text {st }}$ order vibration.

3) Clutch imbalance adjustment: Flat shaped mass block (each weights $5 \mathrm{~g}$ ) was taken as counterweight to avoid affecting the clutch rotation after installation. By adding seven mass blocks, the cultch imbalance amount is adjusted to $470.8 \mathrm{~g} \cdot \mathrm{mm}$.

Then, the imbalance-adjusted clutch was reinstalled to the powertrain rotational system with the original angle of the DMF on Vehicle A. The $1^{\text {st }}$ order vibration levels of the powertrain and the seat rail are recorded and displayed in Tab. 7. It can be seen that the excitation $1^{\text {st }}$ order vibration of the powertrain is reduced from 0.524 to $0.069 \mathrm{~m} / \mathrm{s}^{2}$, which realizes a decline of almost a factor of 7 . For the seat rail, its $1^{\text {st }}$ order vibration drops from 0.122 to $0.016 \mathrm{~m} / \mathrm{s}^{2}$ with an improvement ratio of about $87 \%$. The subjective evaluation score given by engineers goes up to 9 (out of 10). In the subsequent mass production, the imbalance amount can be controlled by optimizing 


Table 7. $1^{\text {st }}$ order vibration results after clutch imbalance adjustment.
\begin{tabular}{|l|l|l|l|l||}
\hline Clutch & Clutch imbalance & Powertrain & Seat rail & Subjective \\
status & $/(\mathrm{g} \cdot \mathrm{mm})$ & $/\left(\mathrm{m} / \mathrm{s}^{\wedge} 2\right)$ & $/\left(\mathrm{m} / \mathrm{s}^{\wedge} 2\right)$ & score \\
\hline Before & 3734.3 & 0.524 & 0.122 & 5 \\
After & 470.8 & 0.069 & 0.016 & 9 \\
\hline
\end{tabular}

the structure and assembly process of the clutch or completely offline inspection.

\section{CONCLUSION}

This paper studied the $1^{\text {st }}$ order abnormal vibration problem at idle condition of a vehicle in development through the excitation sources and transfer paths according to the generation mechanism. Based on comprehensive analyses and detailed experiments, the $1^{\text {st }}$ order abnormal vibration of the malfunctional vehicle was confirmed to be induced by the powertrain rotational system imbalance exceeding a limit due to the clutch imbalance. Then, this is intensified by the resonance of the mounting system. Experiments were carried out on an imbalance test machine, and the magnitude of the $1^{\text {st }}$ order vibration at idle condition was significantly improved after the clutch imbalance adjustment. This paper provides a strong reference for the $1^{\text {st }}$ order abnormal vibration problem analysis and improvement at idle condition for vehicle development.

\section{FUNDING}

This research was funded by National Natural Science Foundation of China (grant NO. 51605291) and Open Foundation of the State Key Laboratory of Fluid Power and Mechatronic Systems (grant NO. GZKF-201806).

On behalf of all authors, the corresponding author states that there is no conflict of interest.

\section{REFERENCES}

1 Govindswamy K., Wolff K. and Heuer S. Aspects of powertrain noise with special emphasis on impulsive noise. $S A E$ paper 2007-01-2411, (2007).

2 Jabeen S.D. Vehicle vibration and passengers comfort. Advances in Computational Intelligence, 357-372, (2017). https://dx.doi.org/10.1007/978-981-10-2525-9

3 Na J., Huang Y., Wu X., et al., Active Adaptive Estimation and Control for Vehicle Suspensions With Prescribed Performance, IEEE Transactions on Control Systems Technology, 26(6), 2063-2077, (2018). https://dx.doi.org/10.1109/TCST.2017.2746060\%20\%20

${ }^{4}$ Lu Z., Wang H., Yao H.L., et al., A Quasi-Static Method for Predicting Vehicle-Road Coupling Vibration Generated by Pavement Unevenness. Journal of Vibration Engineering \& Technologies, 3(2), 223-236, (2015).

5 Ouyang T., Huang H., Zhang N., et al., A model to predict tribo-dynamic performance of a spur gear pair. Tribology International, 116, 449-459, (2017). https://dx.doi.org/10.1016/j.triboint.2017.08.005

6 Ouyang T., Su Z., Li S., et al., Experimental and numerical investigations on dynamic characteristics of gear-roller-bearing system. Tribology International, 140, 730-746, (2019). https://dx.doi.org/10.1016/j.mechmachtheory.2019.06.034

7 Ouyang T., Huang G., Chen J., et al. Investigation of lubricating and dynamic performances for high-speed spur gear based on tribo-dynamic theory. Tribology International, 136, 421-431, (2019). https://dx.doi.org/10.1016/j.triboint.2019.03.009

8 Panza M.A. A review of experimental techniques for NVH analysis on a commercial vehicle. Energy Procedia, 82, 1017-1023, (2015). https://dx.doi.org/10.1016/j.egypro.2015.11.861

9 Sugimura H., Donoue Y., Takei M., et al. Prediction of low frequency vibration caused by power train using multi-body dynamics. SAE paper 2009-01-2193, (2009). https://dx.doi.org/10.4271/2009-01-2193

10 Kalla B., Patil S. and Kumbhar M. Idle shake simulation and optimization through digital car model. SAE paper 2015-01-2368, (2015). https://dx.doi.org/10.4271/2015-01$2368 \% 20$

11 Iyer G., Prasanth B., Wagh S. and Hudson D. Idle vibrations refinement of a passenger car. SAE paper 2011-26-0069, (2011). https://dx.doi.org/10.4271/2011-26-0069

12 Wong P.K., Tam L.M., Li K., et al. Engine idlespeed system modelling and control optimizatdion using artificial intelligence. Proceedings of the Institution of Mechanical Engineers Part D: Journal of Automobile Engineering, 224(1), 55-72, (2010). https://dx.doi.org/10.1243/09544070jauto1196

13 Wang X. Vehicle noise and vibration refinement. Elsevier, (2010).

14 Ajovalasit M., Giacomin J. Analysis of variations in diesel engine idle vibration. Proceedings of the Institution of Mechanical Engineers Part D: Journal of Automobile Engineering, 217(10), 921-933, (2003). https://dx.doi.org/10.1243/095440703769683324

15 Shim Y., Kauh S.K. and Ha K.P. Evaluation of idle stability through in-situ torque measurement in automatic transmission vehicles. International Journal of Automotive Technology, 12(3), 315-320, (2011). https://dx.doi.org/10.1007/s12239-011-0037-5

16 Teng C. Engine idle combustion stability evaluation using calibration parameters. SAE paper 2005-01-2461, (2005). https://dx.doi.org/10.4271/2005-01-2461

17 Wang D.-Y., Zhao X.-Z. and Shangguan W.-B. Design method for a powertrain mounting system to decrease the vehicle key on/off vibrations. Proceedings of the Institution of Mechanical Engineers Part D: Journal of Automobile Engineering, 232(9), 1221-1236, (2018). https://dx.doi.org/10.1177/0954407017728190\%20

18 Fu T., Rakheja S. and Shangguan W.-B.. Design of a hybrid proportional electromagnetic dynamic vibration absorber for control of idling engine vibration. Proceedings of the Institution of Mechanical Engineers Part D: Journal of Automobile Engineering, 234(1), 56-70, (2020). https://dx.doi.org/10.1177/0954407019845720

19 Han S.-B. Investigation of cyclic variations of IMEP under idling operation in spark ignition engines. KSME International Journal, 15(1), 81-87, (2001). https://dx.doi.org/10.1007/bf03184801

20 Teng C. Evaluation of idle combustion stability using flywheel acceleration. SAE paper 2003-01-1673, (2003). https://dx.doi.org/10.4271/2003-01-1673 